\title{
Predation on Artificial Nests of Northern Bobwhites, Colinus virginianus, by Mammalian Mesopredators: Does the Problem-Individual Paradigm Fit?
}

\author{
J. B. Jennings ${ }^{1,4}$, M. L. Kennedy ${ }^{1}$, A. E. Houston ${ }^{2}$, and B. D. CARver ${ }^{3}$ \\ ${ }^{1}$ Ecological Research Center and the Department of Biology, The University of Memphis, Memphis, Tennessee 38152 USA \\ ${ }^{2}$ Ames Plantation, The University of Tennessee, P. O. Box 389, Grand Junction, Tennessee 38039 USA \\ ${ }^{3}$ Department of Biology, Freed-Hardeman University, Henderson, Tennessee 38340 USA \\ ${ }^{4}$ Department of Natural Sciences, Unit 208, Southwest Tennessee Community College, 737 Union Avenue, Memphis, Tennessee \\ 38103 USA
}

Jennings, J. B., M. L. Kennedy, A. E. Houston, and B. D. Carver. 2006. Predation on artificial nests of Northern Bobwhites, Colinus virginianus, by mammalian mesopredators: Does the problem-individual paradigm fit? Canadian Field-Naturalist 120(4): 452-456.

Using mark/recapture procedures, predation on artificial nests of Northern Bobwhites (Colinus virginianus) by mammalian mesopredators (Raccoons, Procyon lotor; Virginia Opossums, Didelphis virginiana; and Striped Skunks, Mephitis mephitis) was assessed in relation to the "problem-individual" paradigm. The paradigm, which is untested among mammalian mesopredators, predicts that most predation on a prey species is by a small number of individuals repeatedly involved. By examining number of captures and recaptures on artificial nests during non-nesting and nesting periods in 2000-2003, predation within and among species were gauged. Results varied by species, sampling period, and year; however, predation was by a small percentage of individuals and only within the population of Striped Skunks were individuals (2 of 49) captured on an artificial nest more than once. Raccoons, Virginia Opossums, and Striped Skunks were responsible for 10, 2, and 12\% of the loss of all nests available to predators, respectively. Based on low occurrences of individuals repeatedly involved in predation on nests, the problemindividual paradigm was unsubstantiated. Although Raccoons, Virginia Opossums, and Striped Skunks (as individual predators) had only moderate impact on the population of Northern Bobwhites, they had a much greater impact collectively (preying upon $24 \%$ of all nests available). To maximize Northern Bobwhite success, the most productive management is probably best directed toward a vertebrate guild that includes mammalian, avian, and reptilian predators, and management strategies that use multiple techniques.

Key Words: Raccoons, Procyon lotor, Striped Skunks, Mephitis mephitis, Virginia Opossums, Didelphis virginiana, Northern Bobwhites, Colinus virginianus, artificial nests, problem individuals, predation, Tennessee.

Due to several factors (e.g., release of predators and reduced hunting; Young and Ruff 1982; Amarasekare 1993; Mosillo et al. 1999), populations of Raccoons (Procyon lotor), Virginia Opossums (Didelphis virginiana), and Striped Skunks (Mephitis mephitis) have increased in abundance throughout much of their range. These increases have caused widespread removal to be attempted as one means of controlling populations of these species (United States Department of Agriculture 2004*). Linnell et al. (1999), in discussing carnivorelivestock conflicts, pointed out that individuals or demographic groups within a predator population can show different behavioral traits where only a small proportion of individuals is accountable for taking significant numbers of a prey species. They refer to the phenomena as the "problem-individual" paradigm. Although this paradigm appears to fit some larger carnivores (Rabinowitz 1986; Ross et al. 1997; Sacks et al. 1999; Stahl et al. 2001), the hypothesis rarely has been tested (Linnell et al. 1999). Presently, the existence of individuals or a demographic group within mid-sized mammalian predators that prey upon a disproportionate number of nests of ground-nesting birds is unknown. Different rates of predation, by individuals or species, could allow for targeted removal of individuals rather than widespread removal as a means of controlling nest predation which may have broad conservation and management application as fewer individual predators would need to be removed.

Mammalian mesopredators are among the known predators of Northern Bobwhites (Colinus virginianus; Leimgruber et al. 1994; Fenske-Crawford and Nieme 1997), and populations of this game bird have declined throughout most of its range (Brennan 1991). However, causes of mortality for Northern Bobwhites are not well understood (Burger et al. 1995), and rates of predation within and among species of mammalian predators on Northern Bobwhites are uncertain. Additionally, midsized mammalian predators have been successfully captured and recaptured in live traps (Johnson 1970; Baldwin et al. 2004) and have been shown to prey upon artificial nests of Northern Bobwhites (Leimgruber et al. 1994; Fenske-Crawford and Niemi 1997); therefore, they make a good model for assessing the "problemindividual" paradigm using capture/recapture procedures.

The purpose of the present study was to examine the "problem-individual" paradigm in light of predation by populations of mammalian mesopredators on artificial nests of Northern Bobwhites. Specifically, the prediction was tested that predation on artificial nests of Northern Bobwhites by Raccoons, Virginia Opossums, 
and Striped Skunks is not widespread within and among species. This work should assist in developing sound conservation and management programs for Northern Bobwhites and control of mammalian mesopredators.

\section{Methods}

This investigation was conducted on the Ames Plantation (Ames; $35^{\circ} 4^{\prime} \mathrm{N}, 89^{\circ} 13^{\prime} \mathrm{W}$ ), an agricultural experiment station of The University of Tennessee and home to the National Field Trial Championship for bird dogs, located in Hardeman and Fayette counties, Tennessee. Ames was approximately 7500 ha and consisted of a mosaic of habitat types that included agricultural fields, pastures, upland hardwoods, bottomland hardwoods, and pine plantations. On the site, about 2000 ha were managed extensively for Northern Bobwhites. The site provided sufficient bird populations (autumn densities of ca. 2-3 birds/ha; Seckinger 2004) and associated predator suite (Leberg and Kennedy 1988; Baldwin 2003; Baldwin et al. 2004) to allow study of a ground nesting bird. For a more detailed description of Ames see Baldwin et al. (2004).

Two study sites (separated by $1.6 \mathrm{~km}$ ) were sampled. Each was $1.6 \mathrm{~km}^{2}$ and was similar in habitat (fragmented, upland hardwood forest interspersed with early successional fields). Because results obtained at each site were similar, results are combined and are presented here. Trapping during the non-nesting season (October-December 2000-2002) was conducted using Raccoon-size live traps $(81.3 \times 25.4 \times 30.5 \mathrm{~cm}$; Tomahawk Live Trap Co., Tomahawk, Wisconsin, or Havahart Live Traps, Woodstream Corporation, Lititz, Pennsylvania), which were baited with cat food and placed in an $8 \times 8$ configuration with traps spaced at about 230 -m intervals. Sampling was conducted for 32 nights/season (for a total of 2000 trap nights/season). Once captured, sex and age were determined, and individuals were tagged (National Band and Tag Company, Newport, Kentucky) in both ears. Additionally, to confirm that individuals remained on the study site during the nesting season, 17, 3, and 3 Raccoons; 10, 9, and 5 Virginia Opossums; and 7,8 , and 1 Striped Skunks were fitted with radiocollars in 2000, 2001, and 2002, respectively. Animals were verified as being on the study site using a threeelement hand-held antenna and a portable receiver. Telemetry equipment was from Advanced Telemetry Systems, Inc., Isanti, Minnesota. All individuals were released at the site of capture. Work during this period provided a known number of marked individuals that could be compared to those individuals captured during the nesting trapping season.

Results obtained during the nesting trapping season (June-September 2001-2003) were derived using artificial nests ( $10 \mathrm{~cm}$ wide by $6 \mathrm{~cm}$ deep) and baited with two eggs of Northern Bobwhites (Hernandez et al. 2001). The nest itself, constructed from wicker, was commercially purchased. Before placement, nests were left outdoors in an undisturbed state for 5-7 days to minimize human odors as suggested by Donalty and Henke (2001). Predators can cue on human odors at artificial nests (Whelan et al. 1994), but this can be minimized by rain or scents (Donalty and Henke 2001). To address this concern, eggs were rinsed with distilled water and handled with rubber gloves when placed on nests (Small and Hunter 1988). By comparing individuals of the known population (non-nesting season captures) that also were captured on artificial nests during the nesting season, the percentage of the population actively involved in predation on artificial nests was determined.

Artificial nests were placed inside live traps. At each site, 80 traps were established; 50 were in actual use at any one time. Traps were placed either selectively or randomly which resulted in an irregular distribution over each of the $1.6 \mathrm{~km}^{2}$ study areas. Because of this placement of traps, artificial nests occurred in a variety of habitat types which can be typical of Northern Bobwhites (Stribling 1996). Traps that were without nests were wired open. All traps were camouflaged with available vegetation. Once a nest was preyed upon, another trap (randomly or selectively placed) in another location had an artificial nest placed inside. Traps with a preyed-upon nest were closed and no longer used. This provided 50 nests on each of the two sites to be in continuous use. Traps in operation were open for 90 nights/season (for a total of 9000 trap nights/season), and were checked daily. To minimize animals associating traps with nests, 25 pseudo-nests were established on each site. These were made of chicken wire in the shape and size of the actual traps used to contain artificial nests. Pseudo-nests were not baited and were randomly placed in the study areas.

\section{Results}

For comparisons between nesting and non-nesting seasons, radiotelemetry procedures confirmed that 9 Raccoons, 1 Virginia Opossum, and 2 Striped Skunks, which were radiocollared during the non-nesting season (2000), were present during the nesting-trapping season (2001). Three Raccoons collared in the nonnesting sessions (2000) along with 1 Striped Skunk were present on the study area for the nesting-trapping session (2002). There also was one Raccoon and one Striped Skunk collared during the non-nesting-trapping session (2002) present on the study area for the nesting-trapping session (2003).

Capture data derived from the two sampling periods varied somewhat by species, year, and sampling period (Table 1). Sampling during the non-nesting period revealed the presence of all target species, with the greatest number of individuals varying by species each year. Sampling during the nesting period also showed presence of all targeted species during each year but in smaller numbers and with less variation in data across years than observed in the non-nesting period. 
TABLE 1. Capture data derived in a study of predation by mammalian mesopredators (Raccoons, Virginia Opossums, Striped Skunks) on artificial nests of Northern Bobwhites during two trapping sessions (non-nesting, nesting) on the Ames Plantation in western Tennessee 2001-2003. $\mathrm{C}=$ number of individuals captured; $\mathrm{R}=$ number of individuals recaptured at least one time during the same trapping session of the same year; $\% \mathrm{R}=$ percentage of marked individuals recaptured $(\mathrm{R} / \mathrm{C} \times 100)$; $\mathrm{M}$ $=$ number of individuals captured $>2$ times $\% \mathrm{COL}=$ the percentage of radio-collared animals captured (number of collared animals recaptured/total number collared $\times 100 \%$ ); $\mathrm{T}=$ number of individuals captured during the non-nesting period that were recaptured during the nesting period; $\% \mathrm{~K}=$ percentage of individuals captured during the non-nesting period that were recaptured during the nesting period (T/C of the Non-nesting period $\times 100 \%$ ).

\begin{tabular}{|c|c|c|c|c|c|c|c|c|c|c|c|c|c|}
\hline \multirow[b]{2}{*}{ Year } & \multirow[b]{2}{*}{ Species } & \multicolumn{5}{|c|}{$\begin{array}{c}\text { Non-nesting } \\
\text { (October-December) }\end{array}$} & \multicolumn{5}{|c|}{$\begin{array}{c}\text { Nesting } \\
\text { (June-September) }\end{array}$} & \multicolumn{2}{|c|}{$\begin{array}{l}\text { Captured during } \\
\text { both seasons }\end{array}$} \\
\hline & & $\mathrm{C}$ & $\mathrm{R}$ & $\% \mathrm{R}$ & M & $\% \mathrm{COL}$ & $\mathrm{C}$ & $\mathrm{R}$ & $\% \mathrm{R}$ & M & $\% \mathrm{COL}$ & $\mathrm{T}$ & $\% \mathrm{~K}$ \\
\hline \multirow[t]{3}{*}{2001} & Raccoon & 41 & 24 & 59 & 6 & 18 & 13 & 0 & 0 & 0 & 11 & 4 & 10 \\
\hline & Virginia Opossum & 33 & 13 & 39 & 8 & 10 & 3 & 0 & 0 & 0 & 0 & 0 & 0 \\
\hline & Striped Skunk & 12 & 5 & 42 & 4 & 43 & 22 & $1^{1}$ & 5 & $1^{1}$ & 0 & 1 & 8 \\
\hline \multirow[t]{3}{*}{2002} & Raccoon & 19 & 8 & 42 & 1 & 0 & 14 & 0 & 0 & 0 & 33 & 0 & 0 \\
\hline & Virginia Opossum & 19 & 9 & 47 & 6 & 0 & 3 & 0 & 0 & 0 & 0 & 0 & 0 \\
\hline & Striped Skunk & 24 & 12 & 50 & 7 & 0 & 11 & 1 & 9 & 0 & 0 & 1 & 4 \\
\hline \multirow[t]{3}{*}{2003} & Raccoon & 38 & 17 & 45 & 4 & 0 & 16 & 0 & 0 & 0 & 0 & 3 & 8 \\
\hline & Virginia Opossum & 89 & 24 & 27 & 9 & 20 & 4 & 0 & 0 & 0 & 0 & 1 & 1 \\
\hline & Striped Skunk & 46 & 18 & 39 & 8 & 0 & 16 & 0 & 0 & 0 & 0 & 0 & 0 \\
\hline
\end{tabular}

${ }^{1}$ This reflects predation by the same individual.

The total number of nests available to predators was 433. Raccoons were responsible for 43 nests preyed upon (10\% of all nests available to predators). Virginia Opossums were responsible for predation on 10 nests (2\%), and Striped Skunks destroyed 52 nests (12\% of all nests available). Collectively, these predators preyed upon $24 \%$ of all available nests. No significant pattern existed in the age or sex of the predators involved in predation on artificial nests.

\section{Discussion}

Results of this study documented that at most only $10 \%$ of a known predator population (Table 1) was actively involved in predation on artificial nests of Northern Bobwhites. Additionally, individual predator species were involved in predation on artificial nests to varying levels (Table 1). Based on these results, the prediction that predation on artificial nests of Northern Bobwhites by Raccoons, Virginia Opossums, and Striped Skunks is not widespread within and among species, is supported, and the "problem-individual" paradigm is unsubstantiated. All predators assessed had members captured multiple times during the non-nesting season. These results were similar to those reported in other studies of mesopredators conducted during autumn and winter (non-nesting seasons) in the region (Ladine 1995; Baldwin 2003). Such results demonstrate that individuals can be captured and recaptured in suitable numbers to explore the "problem-individual" paradigm. However, only two Striped Skunks were captured on artificial nests more than once. Given that these individuals represented only 2 of 49 Striped Skunks captured and were only captured 2 and 3 times, respectively, in the present study and that Vickery et al. (1992) reported predation by Striped Skunks on nests of birds was not targeted, these results do not corroborate the "problem-individual" paradigm. Additionally, in com- parison with larger mammalian predators, this paradigm has been associated, generally, with much higher levels of predation and by greater numbers of individuals repeatedly involved in taking prey (Claar et al. 1986; Stander 1990; Ross et al. 1997; Sacks et al. 1999; Stahl et al. 2001). Scalet et al. (1996) pointed out that predator-prey interactions influence both prey and predator populations. However, based on results of the present study, these interactions appear to be complex and differ among mammalian taxa.

Lack of support for the "problem-individual" paradigm among target predators could be explained by distribution of nests of Northern Bobwhites on the landscape and the predators involved. Stribling (1996) noted that nests of Northern Bobwhites are located in a number of habitat types. Linnell et al. (1999) suggested that a scattered distribution of prey, such as the distribution of artificial nests in this study, would increase encounter rates by predators without any search behavior required, and hypothesized that, under these conditions, problem individuals are less likely to appear because most individuals have opportunity to take the target prey without developing specialized behaviors.

Raccoons, Virginia Opossums, and Striped Skunks are omnivorous and opportunistic predators with strong preferences for seasonally available foods (McManus 1974; Gardner 1982; Godin 1982; Kaufmann 1982; Schwartz and Schwartz 2001). Wiens (1976) discussed population responses to patchy environments and noted the importance of prey density to responses of populations to patchiness. It appears likely that the habitat usually occupied by Northern Bobwhites (forest openings, open woods, fallow fields, and edges of cultivated fields; Stribling 1996) provides favorable and abundant foods (e.g., insects and other invertebrates, wild fruits, and small mammals; Merritt 1987; Schwartz and Schwartz 2001) for mammalian predators. Given that 
number of individuals known alive for each species of predator was greater on the study site during the nonnesting period than the nesting period, as well as overall recapture rate and number of individuals captured more than 2 times (Table 1), it seems that the presence of eggs of Northern Bobwhites and Northern Bobwhites themselves had no unusual attraction for mesopredators. Neither Raccoons nor Virginia Opossums had a significant affinity for fields, which are managed intensively for Northern Bobwhites on Ames, and, because of the lack of individuals recaptured on artificial nests, the problem-individual hypothesis is not supported for these species. However, based on the number of captures in the present study, there was a distinct association between fields and Striped Skunks, which reflects a preference for this habitat (Nowak 1991). These habitats also are good for Northern Bobwhites throughout the year and not just during their breeding season (Stribling 1996). These mesopredators apparently used the study site and adjacent areas during the nesting period of Northern Bobwhites for foods other than those associated with Northern Bobwhites.

Being opportunistic, mesopredators may prey upon nests of Northern Bobwhites when they encounter them. Because of increased protein intake during formation and laying of eggs (Rosene 1969), eggs and Northern Bobwhites themselves represent foods of high nutritional value. However, because Northern Bobwhites on Ames provide only a limited source of food, optimal foraging is likely focused on more abundant and easily captured food items. Eggs and birds probably serve as a valuable supplemental food to more abundant food items. For example, Vickery et al. (1992) reported a positive correlation between predation by Striped Skunks on bird eggs and nestlings when that species was foraging for invertebrates. Such foraging patterns could partly explain reports that birds are preyed upon by Raccoons, Virginia Opossums, and Striped Skunks, although their occurrence in diets of these predators is small (McManus 1974; Kaufmann 1982; Godin 1982; Schwartz and Schwartz 2001).

In the present investigation, there was only one year where the most abundant species captured during the non-nesting season was responsible for the greater numbers of artificial nests preyed upon during the nestingtrapping season (Table 1). It appears that Raccoons, Virginia Opossums, and Striped Skunks, as individual species, had only a moderate impact on artificial nests (Table 1). However, as a subset of the community or mesopredator guild - a collection of species that use common resources in similar ways (Root 1967) - they had a much greater impact. In fact, Nicolaus (1987) stated that Raccoons, along with other mammals and birds, belonged to a guild of nest predators. Of artificial nests preyed upon in this study, Raccoons, Virginia Opossums, and Striped Skunks accounted for 10, 2, and $12 \%$ of losses, respectively. Collectively, there was a $24 \%$ loss of artificial nests attributable to this mesopredator guild.
Overall, the pattern of predation on artificial nests of Northern Bobwhites is apparently driven by a larger vertebrate-predator guild similar to the granivore guild (birds, rodents, and insects) reported in deserts of the southwestern United States (Brown and Davidson 1977). This vertebrate-predator guild, including both mammalian and reptilian predators, also has been documented by Staller et al. (2005). Because of the collective predation rates on artificial nests, most productive management (using multiple techniques; Jiminez and Conover 2001) for ground-nesting birds probably is best directed toward a vertebrate guild that includes not only mammalian predators but avian and reptilian predators as well. Because of the dynamic nature of community interactions (Meffe et al. 1997), it is not likely that single actions will resolve complex predator-prey relationships, which reflect the dynamic nature of the ecological world. At present, interaction among mammalian mesopredators is uncertain (Ladine 1997; Kissell and Kennedy 1992) and the impact of large vertebrate-predator guilds on prey species remains unclear. Future investigations are needed to more clearly understand these ecological issues.

\section{Acknowledgments}

Thanks are extended to T. L. Best, S. B. Franklin, J. W. Grubaugh, and B. A. Simco who provided a critical review of an earlier draft of the manuscript. R. A. Baldwin, B. D. Carver, J. R. Hisey, and R. C. Whittington contributed to numerous aspects of the study. Gratitude also is extended to the Ames Plantation for allowing access to lands under their control. This investigation was a cooperative project that included contributions from the Hobart Ames Foundation, Tennessee Wildlife Resources Agency, and The University of Memphis.

Documents Cited (marked * in text)

United States Department of Agriculture. 2004. Wildlife Services' 2003 annual tables. U.S. Department of Agriculture, Washington, D.C., USA. http://www.aphis.usda.gov/ ws/tables/03table11.pdf.

\section{Literature Cited}

Amarasekare, P. 1993. Potential impact of mammalian nest predators on endemic forest birds of western Mauna Kea, Hawaii. Conservation Biology 7: 316-324.

Baldwin, R. A. 2003. An assessment of microhabitat variables and capture success of selected mammalian mesopredators. M.S. thesis. The University of Memphis, Memphis, Tennessee, USA.

Baldwin, R. A., A. E. Houston, M. L. Kennedy, and P. S. Liu. 2004. An assessment of microhabitat variables and capture success of striped skunks (Mephitis mephitis). Journal of Mammalogy 85: 1068-1076.

Brennan, L. A. 1991. How can we reverse the northern bobwhite population decline? Wildlife Society Bulletin 19: 544-555.

Brown, J. H., and D. W. Davidson. 1977. Competition between seed-eating rodents and ants in desert ecosystems. Science 196: 880-882. 
Burger, L. D., T. V. Dailey, E. W. Kurzejeski, and M. R. Ryan. 1995. Survival and cause-specific mortality of northern bobwhite in Missouri. The Journal of Wildlife Management 59: 401-410.

Claar J. J., R. W. Klaver, and C. W. Servheen. 1986. Grizzly bear management on the Flathead Indian Reservation, Montana. International Conference of Bear Research and Management 6: 203-208.

Donalty, S. M., and S. E. Henke. 2001. Can researchers conceal their scent from predators in artificial nest studies? Wildlife Society Bulletin 29: 814-820.

Fenske-Crawford, T. J., and G. R. Niemi. 1997. Predation of artificial nests at two types of edges in a forest-dominated landscape. The Condor 99: 14-24.

Gardner, A. L. 1982. Virginia Opossum. Pages 3-36 in Wild mammals of North America. Edited by J. A. Chapman and G. A. Feldhamer. The Johns Hopkins University Press, Baltimore, Maryland, USA.

Godin, A. J. 1982. Striped and Hooded Skunks in Wild mammals of North America. Edited by J. A. Chapman and G A. Feldhamer. The Johns Hopkins University Press, Baltimore, Maryland, USA.

Hernandez, F. D., S. E. Henke, N. J. Silvy, and D. Rollins. 2001. Comparison of success between actual northern bobwhite and wild turkey nests and simulated nests. Wildlife Society Bulletin 29: 1212-1218.

Jiminez, J. E., and M. R. Conover. 2001. Ecological approaches to reduce predation on ground-nesting gamebirds and their nests. Wildlife Society Bulletin 29: 62-69.

Johnson, A. S. 1970. Biology of the raccoon (Procyon lotor varius Nelson and Golman) in Alabama. Auburn University Agricultural Experiment Station Bulletin, 402: 1-148.

Kaufmann, J. H. 1982. Raccoon and allies. Pages 567-585 in Wild mammals of North America. Edited by J. A. Chapman and G. A. Feldhamer. The Johns Hopkins University Press, Baltimore, Maryland, USA.

Kissell, R. E., and M. L. Kennedy. 1992. Ecological relationships of co-occurring populations of opossums (Didelphis virginiana) and raccoons (Procyon lotor) in Tennessee. Journal of Mammalogy 73: 808-813.

Ladine, T. A. 1995. Ecology of co-occurring populations of Virginia opossums (Didelphis virginiana) and raccoons (Procyon lotor). Ph.D. dissertation. The University of Memphis, Memphis, Tennessee, USA.

Ladine, T. A. 1997. Activity patterns of co-occurring populations of Virginia opossums (Didelphis virginiana) and raccoons (Procyon lotor). Mammalia 61: 345-354.

Leberg, P. L., and M. L. Kennedy. 1988. Demography and habitat relationships of raccoons in western Tennessee. Proceedings of the Annual Conference of Southeastern Association of Fish and Wildlife Agencies 42: 272-282.

Leimgruber, P., W. J. McShea, and J. H. Rappole. 1994. Predation on artificial nests in large forest blocks. The Journal of Wildlife Management 58: 254-260.

Linnell, J. D. C., J. Odden, M. E. Smith, R. Aanes, and J. E. Swenson. 1999. Large carnivores that kill livestock: do "problem individuals" really exist? Wildlife Society Bulletin 27: 698-705.

McManus, J. J. 1974. Didelphis virginiana. Mammalian Species 40: 1-6.

Meffe, G. K., C. R. Carroll, and Contributors. 1997. Principle of conservation biology, Second Edition. Sinauer Associates, Inc., Boston, Massachusettes, USA.

Merritt, J. F. 1987. Guide to the mammals of Pennsylvania. University of Pittsburgh Press, Pittsburgh, Pennsylvania, USA.
Mosillo, M., E. J. Heske, and J. D. Thompson. 1999. Survival and movements of translocated raccoons in north central Illinois. The Journal of Wildlife Management 63: 278-286.

Nicolaus, L. K. 1987. Conditioned aversions in a guild of egg predators: implications for aposematism and prey defense mimicry. The American Midland Naturalist 117: 405-419.

Nowak, R. M. 1991. Walker's mammals of the world. Volume 2. Fifth Edition. The Johns Hopkins University Press, Baltimore, Maryland, USA.

Rabinowitz, A. R. 1986. Jaguar predation on domestic livestock in Belize. Wildlife Society Bulletin 14: 170-174.

Root, R. B. 1967. The niche exploitation pattern of the bluegray gnatcatcher. Ecological Monographs 37: 317-350.

Rosene, W. 1969. The bobwhite quail: its life and management. Rutgers University Press, Newark, New Jersey, USA.

Ross, P. I., M. G. Jalkotzy, and M. Festa-Bianchet. 1997. Cougar predation on bighorn sheep in southwestern Alberta during winter. Canadian Journal of Zoology 75: 771775 .

Sacks, B. N., M. M. Jaeger, J. C. C. Neale, and D. R. McCullough. 1999. Territoriality and breeding status of coyotes relative to sheep predation. The Journal of Wildlife Management 63: 593-605.

Scalet, C. G., L. D. Flake, and D. W. Willis. 1996. Introduction to wildlife and fisheries: An integrated approach. W. H. Freeman and Company, New York, New York, USA.

Schwartz, C. W., and E. R. Schwartz. 2001. The wild mammals of Missouri. Second Edition. University of Missouri Press and Missouri Department of Conservation, Columbia, Missouri, USA.

Seckinger, E. M. 2004. Effects of landscape composition and structure on northern bobwhite winter and nest survival. M.S. thesis, Mississippi State University, Starkville, Mississippi, USA.

Small, M. F., and M. L. Hunter. 1988. Forest fragmentation and avian nest predation in forested landscapes. Oecologia 76: 62-64.

Stahl, P., J. M. Vandel, V. Herrenschmidt, and P. Migot. 2001. Predation on livestock by an expanding reintroduced lynx population: long-term trend and spatial variability. The Journal of Applied Ecology 38: 674-687.

Staller, E. L., W. E. Palmer, J. P. Carroll, R. P. Thornton, and D. C. Sisson. 2005. Identifying predators at northern bobwhite nests. The Journal of Wildlife Management 69: 124-132.

Stander, P. E. 1990. A suggested management strategy for stock-raiding lions in Namibia. South African Journal of Wildlife Research 20: 37-43.

Stribling, L. 1996. Bobwhite quail management. Alabama Cooperative Extension Service, Auburn University, Alabama, USA. ANR-511: 1-8.

Vickery, P. D., M. L. Hunter, Jr., and J. V. Wells. 1992. Evidence of incidental nest predation and its effects on nests of threatened grassland birds. Oikos 63: 281-288.

Whelan, C. J., M. L. Dilger, D. Robson, N. Hallyn, and S. Dilger. 1994. Effects of olfactory cues on artificial-nest experiments. The Auk 111: 945-952.

Wiens. J. A. 1976. Population responses to patchy environments. Annual Review of Ecology and Systematics 7: 81120.

Young, B. F., and R. L. Ruff. 1982. Population dynamics and movements of black bears in east central Alberta. The Journal of Wildlife Management 46: 845-860.

Received 3 January 2006

Accepted 17 February 2007 